\title{
Chapter 5 \\ Overview of Engineering Mathematics Education for STEM in Armenia
}

\author{
Ishkhan Hovhannisyan
}

The higher education system in Armenia consists of a number of higher education institutions (HEIs), both state and private. State higher education institutions operate under the responsibility of several ministries, but most of them are under the supervision of the Ministry of Education and Science. At present there are 26 state and 41 private higher education institutions operating in the Republic of Armenia, of which 35 are accredited institutions, 6 are non-accredited institutions, 3 are branches of state HEIs and 4 are branches of private HEIs from the Commonwealth of Independent States (CIS). Higher education is provided by many types of institutions: institutes, universities, academies and a conservatory.

The University HEIs are providing higher, postgraduate and supplementary education in different branches of natural and sociological fields, science, technology, and culture, as well as providing opportunities for scientific research and studies.

The institute HEIs are conducting specialized and postgraduate academic programs and research in a number of scientific, economic and cultural branches.

The Academy (educational) HEI's activity is aimed at the development of education, science, technology and culture in an individual sphere; it conducts programs preparing and re-training highly qualified specialists in an individual field, as well as postgraduate academic programs.

The preparation of specialists for Bachelor's, Diploma Specialist's and Master's degrees, as well as postgraduate degrees, including a $\mathrm{PhD}$ student program (research) is implemented within the framework of Higher Education. The main education programs of higher professional education are conducted through various types of teaching: full-time, part-time or external education. The academic year, as a rule, starts on September, ending in May and is comprised of 2 semesters with 16-22 weeks of duration. There are mid-term exams and a final exam at the end of each semester.

I. Hovhannisyan $(\square)$

National Polytechnic University of Armenia (NPUA), Faculty of Applied Mathematics and Physics, Yerevan, Armenia 
ARMENIAN EDUCATION SYSTEM DIAGRAM

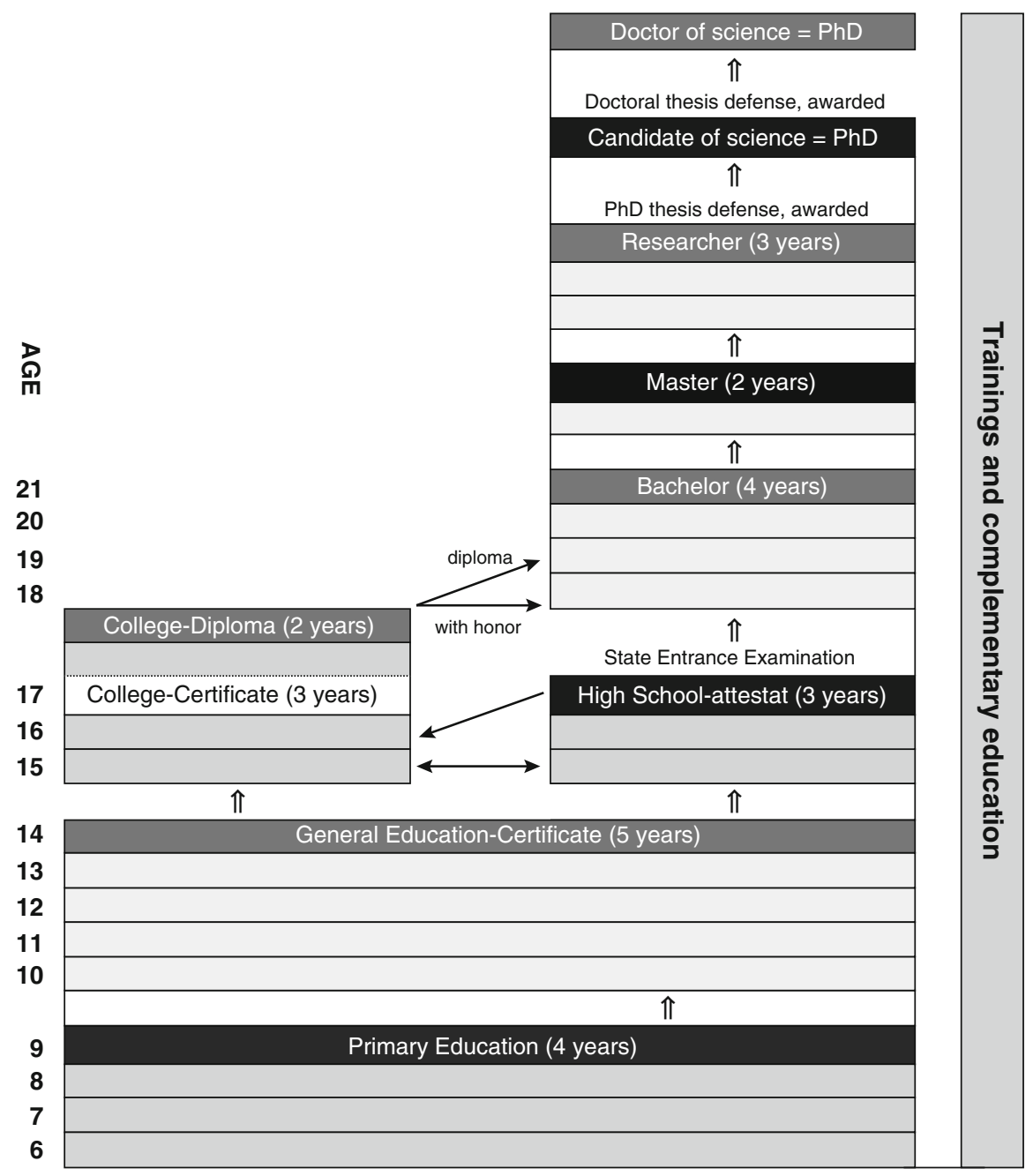

Fig. 5.1 The Armenian education system

The formal weekly workload (contact hours) that students are expected to carry out depends on the type of programs and differs considerably from institution to institution within the country, but common practices are as follows: for Bachelor programs 28-32 h per week (sometimes up to 36), for Master programs 16-18 h and for postgraduate (Doctorate) programs 4-8.

Starting from 2008 all educational programs in Armenia are based on the ECTS. Internal systems of student evaluation and assessment are regulated by the HEIs themselves. Students' learning outcomes are assessed on the basis of examinations 
and tests, which are conducted in writing or orally. The results of examinations are assessed by grading systems varying considerably among institutions (5-, 10-, 20or 100-point marking scales, 4 scale A-F letter grading, etc.). A final evaluation of graduates in state HEIs is conducted by state examination committees both through the comprehensive examination on specialization and defense of graduation work (diploma project, thesis or dissertation) or schemes only one of them is used.

A diagram of the Armenian education system can be seen in Fig. 5.1.

\subsection{National Polytechnic University of Armenia}

The National Polytechnic University of Armenia (NPUA) is the largest engineering institution in Armenia.

The University has a leading role in reforming the higher education system in Armenia. NPUA was the first HEI in RA that introduced three level higher education systems, implemented the European Credit Transfer System (ECTS) in accordance with the developments of the Bologna Process.

The University is a member of European University Association (EUA), the Mediterranean Universities Network, and the Black Sea Universities Network. It is also involved in many European and other international academic and research programs. The University aspires to become an institution, where the entrance and educational resources are accessible to diverse social and age groups of learners, to both local and international students, as well as to become an institution which is guided by a global prospective and moves toward internationalization and European integration of its educational and research systems.

\subsection{Overview of Mathematics Education at NPUA}

The NPUA Faculty of Applied Mathematics and Physics is responsible for major and minor mathematical education at the University. It was established in 1992 by uniting University's 3 chairs of Higher Mathematics. Academician of National Academy of Sciences Prof. Vanik Zakaryan is the founder-Dean of the Faculty. Nowadays the faculty is one of the top centers of Mathematics and Physics in the country and the biggest faculty in the University, having more than 90 full-time faculty members (12 professors and 48 associate professors). The student body of the faculty consists of approximately 200 majors (all programs) and more than 3000 minors. The faculty offers the following programs as majors:

- Bachelor in Informatics and Applied Mathematics;

- Bachelor in Applied Mathematics and Physics;

- Master in Informatics and Applied Mathematics;

- $\mathrm{PhD}$ in Mathematics. 
In addition to these major programs, the Faculty caters to the mathematics and physics subsidiary (minor) courses in other BSc and MSc programs of the University with specializations in Engineering, Industrial Economics and Management. It also renders services of its full-time faculty to teach elective courses of mathematics at $\mathrm{MSc}$ and $\mathrm{PhD}$ programs.

\subsection{Mathematics Courses at NPUA}

The Bachelors of Science in Engineering (BSE) degree at NPUA involves completing 240 credit hours of courses in various categories, which include: a module of languages, Economics and Humanities module, a module of General Engineering courses, Module of Specialization courses, and a module of Math and Natural Science courses. The University requires that all engineering students, regardless of their proposed engineering major, complete specific courses in the core subjects of mathematics which are listed in Table 5.1 with the number of ECTS credits for each course.

Table 5.1 BSc mathematics courses at NPUA

\begin{tabular}{l|l|l|l}
\hline Course & Semester & Credits & Hours \\
\hline $\begin{array}{l}\text { Mathematical Analysis 1 (An } \\
\text { introduction to the concepts of } \\
\text { limit, continuity and derivative, } \\
\text { mean value theorem, and } \\
\text { applications of derivatives such as } \\
\text { velocity, acceleration, } \\
\text { maximization, and curve } \\
\text { sketching) }\end{array}$ & 1 & 5 & $\begin{array}{l}\text { Lectures 32, } \\
\text { tutorials 32 }\end{array}$ \\
\hline $\begin{array}{l}\text { Mathematical Analysis 2 } \\
\text { (introduction to the Riemann } \\
\text { integral, methods of integration, } \\
\text { applications of the integral, } \\
\text { functions of several variables, } \\
\text { partial derivatives, line, surface } \\
\text { and volume integrals) }\end{array}$ & 2 & 5 & tutorials 32, \\
\hline $\begin{array}{l}\text { Analytic Geometry and Linear } \\
\text { Algebra (vector spaces and matrix } \\
\text { algebra, matrices and } \\
\text { determinants, systems of linear } \\
\text { equations) }\end{array}$ & 1 & & \\
\hline $\begin{array}{l}\text { Theory of Probability and } \\
\text { Statistical Methods (probability } \\
\text { space axioms; random variables } \\
\text { and their distributions, } \\
\text { expectation values and other } \\
\text { characteristics of distributions) }\end{array}$ & 3 & 4 & tutorials 16, \\
\hline $\begin{array}{l}\text { Discrete Mathematics } \\
\text { thectures 32, }\end{array}$ & 2 & 4 & \\
\hline
\end{tabular}


Table 5.2 MSc mathematics courses at NPUA

\begin{tabular}{l|l|l|l}
\hline Course & Semester & Credits & Hours \\
\hline Discrete Mathematics & 1 & 5 & $\begin{array}{l}\text { Lectures 48, } \\
\text { practices 16 }\end{array}$ \\
\hline Numerical Methods & 1 & 5 & $\begin{array}{l}\text { Lectures 48, } \\
\text { practices 16 }\end{array}$ \\
\hline Mathematical Programming & 1 & 5 & $\begin{array}{l}\text { Lectures 48, } \\
\text { practices 16 }\end{array}$ \\
\hline Linear Algebra & 1 & 5 & $\begin{array}{l}\text { Lectures 48, } \\
\text { practices 16 }\end{array}$ \\
\hline $\begin{array}{l}\text { Theory of Probability and } \\
\text { Statistical Methods }\end{array}$ & 1 & 5 & $\begin{array}{l}\text { Lectures 48, } \\
\text { practices 16 }\end{array}$ \\
\hline $\begin{array}{l}\text { Functions Approximation by } \\
\text { Polynomials }\end{array}$ & 1 & 5 & $\begin{array}{l}\text { Lectures 48, } \\
\text { practices 16 }\end{array}$ \\
\hline
\end{tabular}

In addition to the core mathematics courses, the Master of Science in Engineering (MSE) degree requires students to complete at least 5 credits of advanced mathematics elective courses. Table 5.2 contains the list of advanced mathematics elective courses for MSE students.

Open Access This chapter is licensed under the terms of the Creative Commons Attribution 4.0 International License (http://creativecommons.org/licenses/by/4.0/), which permits use, sharing, adaptation, distribution and reproduction in any medium or format, as long as you give appropriate credit to the original author(s) and the source, provide a link to the Creative Commons license and indicate if changes were made.

The images or other third party material in this chapter are included in the chapter's Creative Commons license, unless indicated otherwise in a credit line to the material. If material is not included in the chapter's Creative Commons license and your intended use is not permitted by statutory regulation or exceeds the permitted use, you will need to obtain permission directly from the copyright holder.

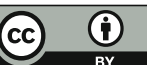

